\title{
Subendocardial Haemorrhage and E.C.G. Changes in Intracranial Bleeding
}

\author{
PENTTI KOSKELO,* M.D. ; SVEN PUNSAR,† M.D.; WALTER SIPILÄ,‡ M.D.
}

E.C.G. changes in connexion with intracranial (especially subarachnoidal) bleeding resembling those in myocardial infarction were first described by Burch et al. in 1954. The most typical change is a deep and broad T-U fusion wave in several leads. The explanation of the changes cbserved remains obscure (Effert et al., 1961).

The purpose of this paper is to discuss the genesis of these E.C.G. changes on the basis of three cases in which both the typical E.C.G. changes and subendocardial haemorrhages were found.

\section{Case 1}

\section{Case Reports}

A 54-year-old housewife who had previously been in good health was admitted on 29 November 1959. For the last three years she had gone swimming in winter-time in a hole cut in the ice-a type of winter sport not uncommon in Finland. After one such swim she suddenly collapsed and was brought to the hospital. Examination on admission showed a well-nourished woman with severe pulmonary oedema. The heart sounds were distant and there were no murmurs. Blood-pressure was 185/105 mm. Hg. Consciousness was clear and there were no signs of pareses. The E.C.G. on admission showed slightly negative $T$-waves in leads I, II, and $V_{4}$ through $V_{6}$. A myocardial infarction was suspected.

She recovered quickly from the pulmonary oedema and felt better, except for increasing headache. On the following morning a slight stiffness of the neck was noticed and a lumbar puncture revealed bloody spinal fluid. A subarachnoidal haemorrhage was diagnosed. An E.C.G. now showed deep and wide negative T-U fusion waves in all leads except lead III, aVR, and $V_{1}$, in which the fusion wave was positive (see Fig.). S.G.O.T. was normal on two successive days.

During the days that followed the headache gradually diminished, the blood content of the spinal fluid decreased, and the E.C.G. changes became less severe. On the eighth day in hospital she had a second intracranial haemorrhage and died two days later.

Necropsy revealed a ruptured aneurysm of the left internal carotid artery at the junction of the posterior communicating and middle cerebral arteries. The left temporal lobe showed some oedema and a few petechiae. The heart weighed $375 \mathrm{~g}$. The coronary arteries were fully open and devoid of any atherosclerosis. The myocardium and the heart valves were macroscopically normal. Numerous small and confluent spots of subendocardial haemorrhages were seen at the left ventricular side of the interventricular septum.

\section{Case 2}

A 60-year-old divorced woman; whose history was negative except for chronic headache, was admitted on 13 September 1961 because of a sudden loss of consciousness. Clinical examination showed an obese woman. Heart sounds were normal, and there were no murmurs. Blood-pressure was $140 / 100 \mathrm{~mm}$. Hg. Lungs were clear on auscultation. She regained consciousness in a few hours. No pareses were present. Examination of spinal fluid revealed a high erythrocyte content. The diagnosis of a sub-

\footnotetext{
* Lecturer in Medicine, University of Helsinki.

† Senior Registrar, University of Helsinki.

‡ Senior Registrar, Kivelä Hospital, Helsinki.
}

arachnoid haemorrhage was made. An E.C.G. taken on the first day in hospital showed biphasic or negative $T-U$ fusion waves in leads I, II, aVL, and $V_{2}$ through $V_{6}$ and a positive $T-U$ fusion , wave in lead aVR. QRS was somewhat notched in leads I, II, aVR, and aVL. The E.C.G. changes were more marked two days later (see Fig.) and thereafter began to show some improvement.

The patient became subjectively symptomless in a few days. On the seventeenth day in the hospital she suddenly developed pulmonary oedema, lost consciousness, and died in a few hours.

Necropsy revealed a ruptured aneurysm of the right middle cerebral artery at its first major division and a haematoma $5 \mathrm{~cm}$. in diameter in the right cerebral hemisphere. The heart weighed $500 \mathrm{~g}$. The left ventricle was slightly hypertrophied. The myocardium and the heart valves were macroscopically normal. The coronary arteries were fully open and they were only slightly atheromatous. Several petechial haemorrhages were seen under the left ventricular endocardium, mainly at the septum and the papillary muscles.

\section{Case 3}

A 65-year-old married woman was admitted on 2 July 1960 because of a left-sided hemiparesis and loss of consciousness. Her blood-pressure had been raised for several years. Examination showed a well-nourished woman. Heart and lungs were normal on auscultation. Blood-pressure was $235 / 130 \mathrm{~mm}$. Hg. The liver was palpable three fingerbreadths below the costal margin. There was no oedema. Spinal fluid was clear on admission but later contained blood. Serum potassium was normal. An E.C.G. on admission (see Fig.) revealed flat $T$-waves in leads I, II, aVR, aVL, and $V_{6}$. Deep negative $T$-waves were present in leads $V_{1}$ through $V_{5}$. High $R$-waves suggested the presence of left ventricular hypertrophy. The $\mathrm{T}$ changes were much less pronounced three days later.

She died on the fifth day in hospital without gaining consciousness. At necropsy a massive haemorrhage was found in the right cerebral hemisphere. The heart weighed $310 \mathrm{~g}$. The coronary arteries were moderately atheromatous but not obstructed. The myocardium and the valves were macroscopically normal. Several small subendocardial haemorrhages were seen at the left side of the interventricular septum and at the anterior wall of the left ventricle.

To sum up, the three cases presented above showed changes in the E.C.G. typical of those described in intracranial bleeding, and at necropsy subendocardial haemorrhages in the left chamber of the heart.

The E.C.G. changes found in connexion with intracranial bleeding appear to resemble those encountered in a purely subendocardial infarction (Georas et al., 1963), rather rarely seen. To demonstrate the striking similarity between the E.C.G. changes in these two conditions the following case with subendocardial infarction is presented. The diagnosis was based on a history of typical chest pain and E.C.G., since this kind of infarction often does not result in other findings.

\section{Case 4}

A 57-year-old clerk, an active sportsman, was admitted to hospital on 31 December 1959 because of progressive anginal pain of two weeks' duration. He was of normal build and in no distress. 
Blood-pressure was 140/100 mm. Hg. Heart sounds were normal and there were no murmurs. Lungs were clear on auscultation. There were no signs of neurological disorders.

The E.C.G. on the second hospital day revealed negative, biphasic, or flat $\mathrm{T}$-waves in leads I, II, aVR, aVL, and $\mathrm{V}_{1}$ through $V_{5}$. The changes were most marked in leads $V_{2}$ through $V_{4}$. (see Fig.). The QRS complexes were normal. Three weeks later slight changes were present in leads $V_{3}$ and $V_{4}$ only. Signs of inflammatory reaction and an elevation of S.G.O.T. were absent. A diagnosis of a subendocardial infarction was made. The size and shape of the heart were normal on radiographic examination. The patient was discharged for convalescence on 22 January 1960 . He was readmitted on 10 July 1960 because of severe chest pain of half a day's duration, and died suddenly a few hours later.

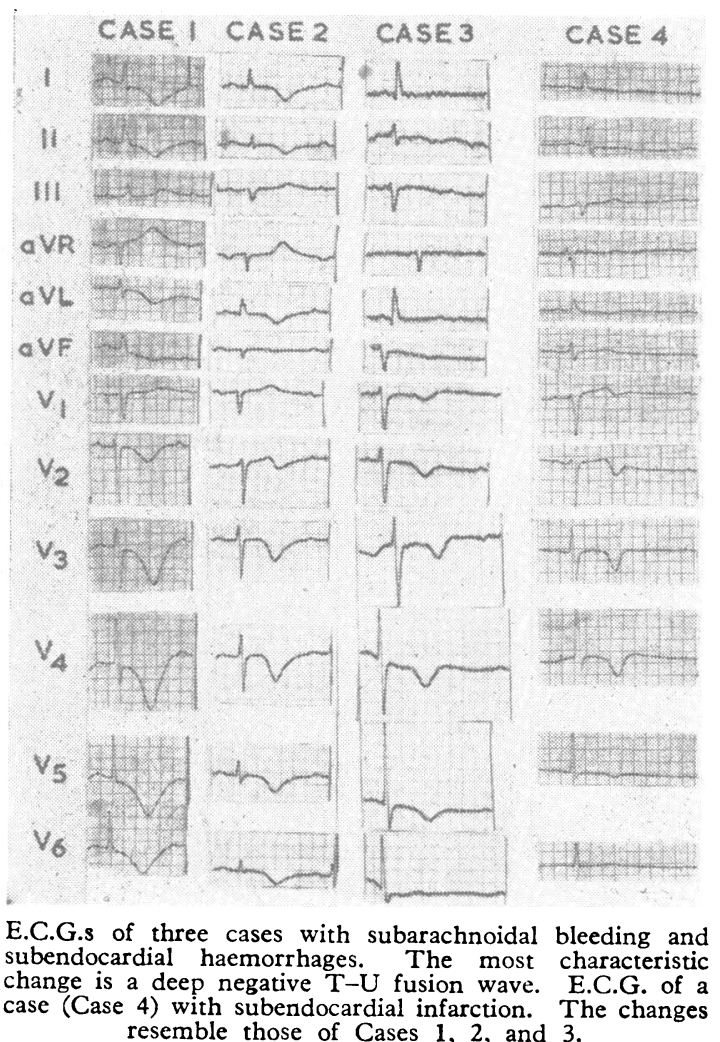

At necropsy the heart weighed $290 \mathrm{~g}$. The coronary arteries were severely atheromatous and narrowed. The left coronary artery was most severely affected but not completely occluded, and a recent anteroseptal infarction was present. In addition to the infarction there was subendocardial scarring in the left side of the interventricular septum, pointing to an old infarction in that area. This was probably the cause of the E.C.G. changes seen half a year earlier. There was no intracranial abnormality.

\section{Discussion}

Burch et al. (1954) suggested that abnormalities of the electrolyte metabolism might be responsible for the E.C.G. findings frequently seen in connexion with intracranial haemorrhages. Popov (1955) attributed the E.C.G. abnormalities to a nervous mechanism. Cropp and Manning (1960) suggested that they are caused by lesions in a certain area of the orbital surface of the frontal lobe of the brain.
Porter et al. (1962) were able to induce in cats similar E.C.G. abnormalities by stimulation of the ventral hippocampus and the medial nuclei of the amygdala. In a few cases in which necropsy has been performed, no specific reason for the E.C.G. abnormalities has been found in the heart (Levine, 1953 ; Wasserman et al., 1956 ; Beard et al., 1959 ; Burch et al., 1960 ; Cropp and Manning, 1960 ; Shuster, 1960).

The E.C.G. changes encountered in intracranial haemorrhage are similar to those sometimes seen in connexion with myocardial infarction confined to the subendocardial layer only. Therefore one could expect a lesion situated in the subendocardium. Haemorrhages located in the subendocardium were present in the cases described above. It has also been previously demonstrated that haemorrhages, limited to the subendocardial tissue of the left ventricle, are commonly found in association with an acute intracranial lesion but are only rarely encountered in other pathological states (Smith and Tcmlinson, 1954). They are most frequent in conditions where there has been a sudden rise in intracranial pressure. This may result in bradycardia and an acute increase in blood-pressure, followed by a sudden rise in left ventricular pressure and anoxia of the subendocardial layer of this chamber. It may be noted, also, that prolonged vagal stimulation in experimental conditions has been shown to lead to subendocardial haemorrhage and degeneration of the myocardium (Eppinger and Rothberger, 1910 ; Manning et al., 1937).

Contrary to earlier explanations, we believe, then, that the E.C.G. changes found in connexion with intracranial bleeding are caused by cardiac lesions and that they do not simulate myocardial ischaemia or injury but are in fact signs of them.

\section{Summary}

Three cases with subarachnoidal bleeding and E.C.G. changes showed at necropsy subendocardial haemorrhages of the heart. It is suggested that the E.C.G. changes described in connexion with intracranial bleeding originate from cardiac ischaemia or injury. One case with a subendocardial infarction is presented to demonstrate the similarity of the E.C.G. changes in a purely cardiac condition.

\section{REFERENCES}

Beard, E. F., Robertson, J. W., and Robertson, R. C. L. (1959). Amer Heart f., 58, 755 .

Burch, G. E., De Pasquale, N., and Malaret, G. (1960). Ann. intern. Med., 52, 587.

- Meyers, R., and Abildskov, J. A. (1954). Circulation, 9, 719.

Cropp, G. J., and Manning, G. W. (1960). Ibid., 22, 25.

Effert, S., Grosse-Brockhoff, F., and Rippert, R. (1961). Dtsch. med. W schr., 86, 1508 .

Eppinger, H., and Rothberger, J. (1910). Quoted by Smith and Tomlinson (1954).

Georas, C. S., Dahlquist, E., Cutts, F. B., and Providence, R. I. (1963). Arch. intern. Med., 111, 488.

Levine, H. D. (1953). Amer. F. Med., 15, 344.

Manning, G. W., Hall, G. E., and Banting, F. G. (1937). Canad. med. Ass. F., 37, 314.

Popov, V. G. (1955). Quoted by Simonson, E. (1958). Ann. Rev.

Porter, R. W., Kamikawa, K., and Greenhoot, J. H. (1962). Amer. Heart 7., 64, 815

Shuster, S. (1960). Brit. Heart f., 22, 316.

Smith, R. P., and Tomlinson, B. E. (1954). F. Path. Bact., 68, 327.

Wasserman, F., Choquette, G., Cassinelli, R., and Bellet, S. (1956). Amer. F. med. Sci., 231, 502. 